\title{
Design and Implementation of Comprehensive Surveillance on Provincial Levels Transmission Network
}

\author{
WANG Chunying, WANG Shiwen, Sheng Lei, Zhang Ningning, AN Zhiyuan \\ and LI Wencui
}

Information\& Telecommunication Co. of State Grid Henan Electric Power Company, Zhengzhou 450052, China

Keywords: Optical Transport Network; Synchronous Digital Hierarchy; TMS; communication resource management system; power communication network

\begin{abstract}
As the OTN (Optical Transport Network) and SDH (Synchronous Digital Hierarchy) network lack the uniform monitoring system to monitor the ever-growing business, this article has presented that use existing TMS to monitor provincial levels transmission network's double plane. While inspected and commanded by the TMS, dispatchers can discover in time and handle the communication failure. The fault effect is reduced to a minimum, the ratio of the equipment and service assurance has greatly increased in safe operation.
\end{abstract}

\section{Introduction}

The electric power communication network, as the special communication network of electric power industrial, needs to transmit copious information of the electric power production, dispatching as well as business management. Support of electric power industrial operation and maintenance management, is one of the fundamental establishment. The information includes not only traditional business, such as administration telephone, dispatching telephone, automation, the management information business of safe production. But also the multimedia messaging business, such as telephone conference, video, broadcast, office automation and IP phones.

\section{State of Monitoring System on Provincial Levels'transmission Network}

As the dual plane, dual converge and dual uplink architecture in the provincial levels' transmission network, the core layer and backbone layer use the loop network architecture. The access layer uses the loop network or two aspects architecture to connect with the core layer and backbone layer. The SW-A of provincial levels' transmission network, which is currently the main carriers of production control business, takes MSTP/SDH technical system. The SW-B of provincial levels' transmission network, which is currently the main carriers of management information business, takes OTN technical system.

At present, TMS, which uses the northbound interface to collect the information of SDH transmission network, not only achieve centralized monitoring of SDH transmission network but also save the manpower and the material resources.

With so many applications of OTN technical system on provincial levels' transmission network, the OTN network administration should be accessed to TMS for unified monitoring and managing. And then the TMS can achieve benefit of integrated network administrators and integrated monitoring fundamentally.

\section{The Combination of TMS and OTN}

The Business Objects of OTN Real Time Monitoring. The business objects of OTN real time monitoring, which include power supply unit, hardware operations, light path, performance parameters of branch and line and network administration, mainly achieve monitor through alarms reported by TMS. 
The Business Hierarchical of OTN Real Time Monitoring. The business hierarchical of OTN real time monitoring has four different levels: emergency, major, secondary and warning.

Emergency means that OTN system security significantly decreases, affected the carrier services. The affecting factors include light path interrupts, component failure, configuration errors or a sharp deterioration in machine room conditions.

Major means that OTN system security cannot be guaranteed due to performance degradation of light path, abnormal appliance components, or over temperature in machine room conditions. The carrier services maybe be affected.

Secondary means that OTN system is unusual due to the exception of light path, appliance components, or temperature in machine room conditions. The carrier services cannot be affected.

Warning means that there are potential problems in OTN system which are caused by unusual action configuration, abnormal appliance components and all.

The Access of OTN Network Administrators. Make the OTN network administrators opened to TMS, so the TMS can monitor the OTN transmission network and carry out rearrangement on resource. The northbound interface shall meet the following limits:

The northbound interface of network administrators shall meet TMF814 standards, which can provide complete and accurate configurations, warnings and performance data.

The northbound interface designed of the network administrators needs to meet the following performance metrics: configuration synchronization time below 20 minutes level per hundred network elements; warning synchronization time below 3 minutes level per hundred network elements; delay time of warning information below 1 second.

Then north bound interface of network administrators support multipoint access technologies.

Throughout the upgrade process of the network administrators, management data can be synchronized in inconsistent and uniqueness fashion. And also the northbound interface can be upgrade synchronously.

Import of Static Resource Information. The static resource information of OTN transmission network, which includes space resource, appliance components, cable resource, wire resource, line corridor resource, wiring resource, telecommunication power supply resource, are input manually.

Association of Static Resource Information and Dynamic Resource Information. The dynamic resource information, which includes device information, device configuration information, device attributes, optical path information, business channels and slot,is collected from network administrators. And then set up relationships between machine rooms and device, device ports and wiring terminals, optical path and transport information, circuit and business, circuit and electricity net operating mode. The association of static resource information and dynamic resource information structure is shown in Figure.1.

\section{Comprehensive Surveillance on Provincial Levels’transmission Network}

TMS use the northbound interface of network administrators to collect the configurations and warnings data from OTN network administrators, and then carry out alarms filtered, alarms redefined, alarms confirmed, alarms inquired and statistical analysis. In this way, the system achieves the success of comprehensive surveillance and management on OTN transmission network. The functional structure of real time monitoring is shown in Figure.2.

When the OTN system failure, the system will report the warning to OTN network administration which will send the warning information to TMS, and then dispatcher will receive warning by TMS. Through the betimes and right collection information of warning information, the data support can be provided for locating fault time exactly. The acquisition of information of OTN network administration and SDH network administration from TMS are independent.

\section{Conclusion}

This article has presented that use existing TMS to manage the OTN transmission network, monitor provincial levels transmission network's double plane. While inspected and commanded by 
the TMS, dispatchers can discover in time and handle the communication failure. The fault effect is reduced to a minimum, the ratio of the equipment and service assurance has greatly increased in safe operation.

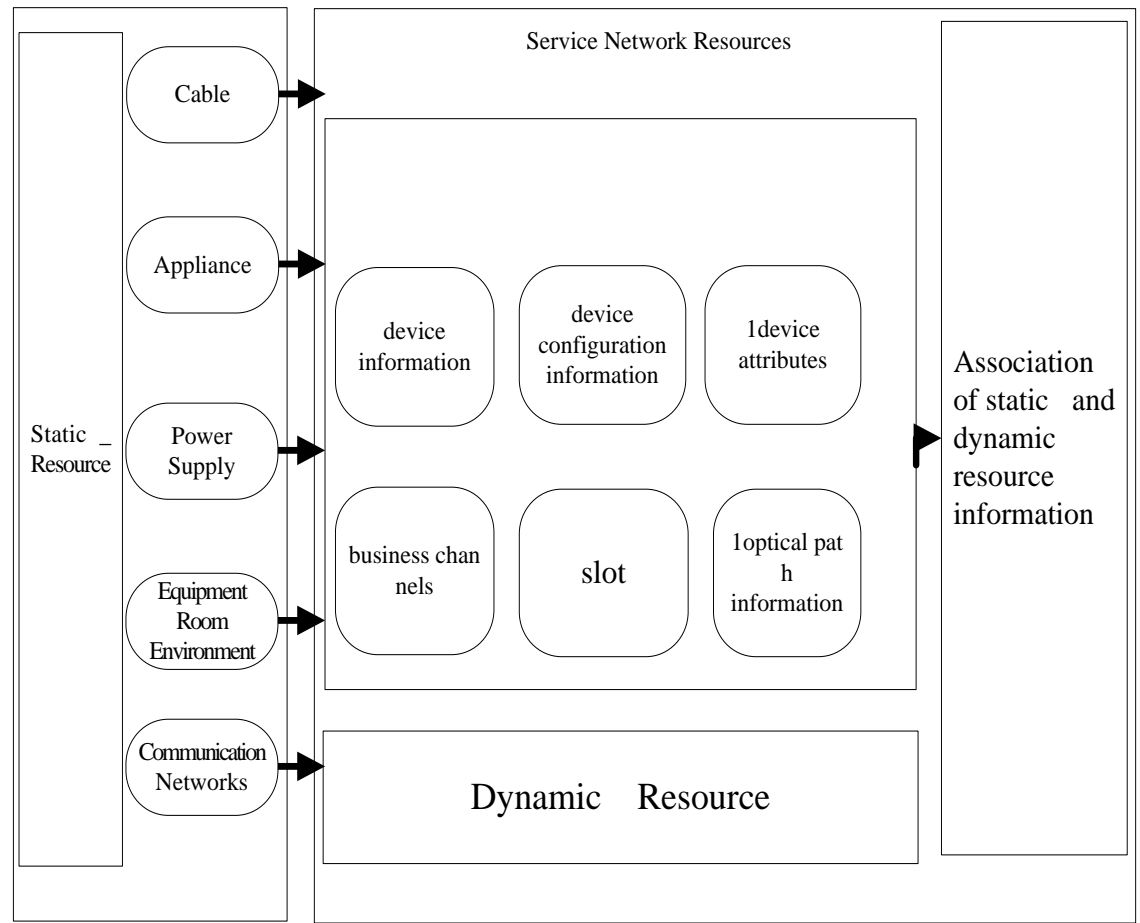

Fig. 1 the association of static and dynamic resource information structure

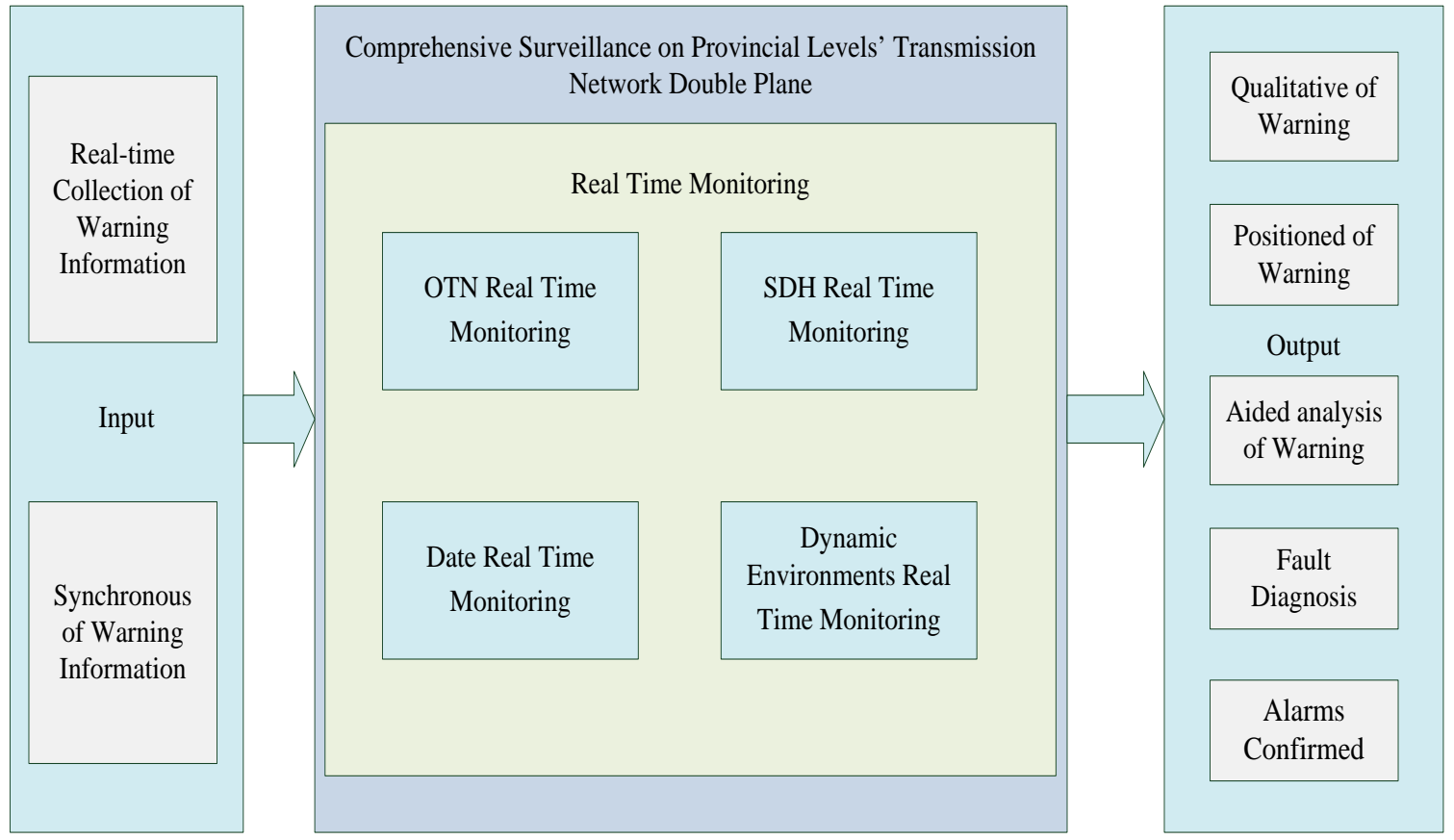

Fig.2 the functional structure of real time monitoring

\section{References}

[1] CHEN Hong-yan, YUAN Hui, ZHANG Xiang-dong. Applicationsof OTN with PTN and SDH technologies in electric powercommunication networks[J]. Study on Optical Communications, 
2013(4): 24-27

[2] LIU Yu-jie, XIAO Jun, DING Chi-wu, et al. Progress and key technologies of OTN[J]. Optical Communication Technology, 2009, 33(6): 36-39

[3] WANG Ye, MIAO Chen-guan. Next-generation transmission network OTN[J]. Communications Technology, 2009, 42(5): 152-154.

[4] LI Hui, ZHANG Yu. Research and Implementation of the Integrated Monitoring System forYunnan Backbone OTN[J]. Electric Power Information and Communication Technology, 2015, 13(12): 45-49. 